\title{
Analisis Tingkat Kesuburan Tanah Melalui Nilai Suseptibilitas Magnetik Pada Lahan Persawahan Kecamatan Gunung Talang Kabupaten Solok
}

\author{
Falzi Rolandio*, Arif Budiman \\ Laboratorium Fisika Bumi, Jurusan Fisika \\ Fakultas Matematika dan Ilmu Pengetahuan Alam Universitas Andalas \\ Kampus Unand LimauManis, Padang, 25163 Indonesia \\ *falzirolandio@gmail.com
}

\begin{abstract}
ABSTRAK
Telah dilakukan analisis suseptibilitas magnetik tanah lapisan atas sebagai parameter kesuburan tanah pada lahan persawahan di Kecamatan Gunung Talang Kabupaten Solok. Sampel tanah diambil sebanyak 10 titik masing-masing di empat lahan persawahan yang berada di Nagari Sukarami (lahan A), Nagari Guguak (lahan B), Nagari Talang (lahan C), dan Nagari Koto Baru (lahan D), serta satu titik pada lahan kosong. Pengambilan sampel diambil pada kedalaman $15 \mathrm{~cm}$ pada setiap titik pengambilan sampel. Pengukuran suseptibilitas magnetik menggunakan MS2B Bartington Susceptibility Meter dengan dua frekuensi, yaitu $0,47 \mathrm{kHz}$ low frequency (LF) dan $4,7 \mathrm{kHz}$ high frequency (HF). Lahan A memiliki nilai suseptibilitas magnetik $\left(\chi_{\mathrm{LF}}\right)$ rata-rata $157,5 \times 10^{-8} \mathrm{~m}^{3} / \mathrm{kg}$, lahan B dengan rata-rata $221,3 \times 10^{-8} \mathrm{~m}^{3} / \mathrm{kg}$, lahan $\mathrm{C}$ dengan rata-rata $222,3 \times 10^{-8} \mathrm{~m}^{3} / \mathrm{kg}$, lahan $\mathrm{D}$ dengan rata-rata $162,6 \times 10^{-8} \mathrm{~m}^{3} / \mathrm{kg}$, lahan kosong dengan nilai $570,5 \times 10^{-8} \mathrm{~m}^{3} / \mathrm{kg}$. Hasil uji XRF menunjukkan bahwa mineral magnetik yang terdapat pada semua lokasi lahan pengambilan sampel adalah hematit $\left(\mathrm{Fe}_{2} \mathrm{O}_{3}\right)$. Semakin tinggi nilai suseptibilitas magnetik maka semakin tinggi kandungan $\mathrm{Fe}$ dalam tanah. Lokasi pengambilan sampel memiliki kandungan $\mathrm{Fe}$ yang normal, sehingga masih layak untuk dijadikan lahan pertanian. Berbeda dengan lahan kosong yang kelebihan Fe, sehingga perlu diberi tambahan pupuk agar kandungan Fe kembali pada keadaaan normal. Lahan persawahan dan lahan kosong memiliki nilai $\chi_{\mathrm{FD}}(\%)$ kurang dari $2 \%$, sehingga masih memiliki kondisi kesuburan yang baik untuk bercocok tanam.

Kata kunci: kesuburan tanah, suseptibilitas magnetik, Fe, hematit
\end{abstract}

\begin{abstract}
An analysis of the magnetic susceptibility of topsoil has been carried out as a parameter of soil fertility in paddy fields in Gunung Talang District, Solok Regency. Soil samples were taken as many as 10 points each in four rice fields located in Nagari Sukarami (land A), Nagari Guguak (land B), Nagari Talang (land C), and Nagari Koto Baru (land D), and one point empty land. Sampling was taken at a depth of 15 $\mathrm{cm}$ at each sampling point. Measurement of magnetic susceptibility using the Bartington Susceptibility Meter MS2B with two frequencies, namely $0.47 \mathrm{kHz}$ low frequency (LF) and $4.7 \mathrm{kHz}$ high frequency $(H F)$. Land A has a magnetic susceptibility value $\left(\chi_{L F}\right)$ an average of $157.5 \times 10^{-8} \mathrm{~m}^{3} / \mathrm{kg}$, land $B$ with an average of $221.3 \times 10^{-8} \mathrm{~m}^{3} / \mathrm{kg}$, land $C$ with an average of $222.3 \times 10^{-8} \mathrm{~m}^{3} / \mathrm{kg}$, land D with an average of $162.6 \times 10^{-8} \mathrm{~m}^{3} / \mathrm{kg}$, empty land with a value of $570.5 \times 10^{-8} \mathrm{~m}^{3} / \mathrm{kg}$. The XRF test results showed that the magnetic minerals found in all sampling locations were hematite $\left(\mathrm{Fe}_{2} \mathrm{O}_{3}\right)$. The higher the value of magnetic susceptibility, the higher the Fe content in the soil. The sampling location has a normal Fe content, so it is still suitable to be used as agricultural land. It is different from empty land which has an excess of Fe, so it needs to be given additional fertilizer so that the Fe content returns to normal conditions. Rice fields and empty land have a value of $\chi_{F D}(\%)$ of less than $2 \%$, so they still have good fertility conditions for farming.

Keywords: soil fertility, magnetic susceptibility, Fe, hematite
\end{abstract}

\section{PENDAHULUAN}

Tanah adalah lapisan permukaan bumi hasil dari perubahan bentuk dan lokasi zat-zat mineral baik organik maupun anorganik yang proses pembentukannya dipengaruhi oleh faktorfaktor lingkungan dalam waktu yang sangat panjang (Schroeder, 1984). Tanah yang subur adalah tanah yang secara kimia memiliki $\mathrm{pH}$ yang netral dan kandungan unsur hara yang cukup, dan secara fisik memiliki tekstur lempung, konsistensi gembur, dan porositas baik. Unsur hara yang terdapat dalam tanah terbagi dua yaitu unsur hara makro dan unsur hara mikro. Unsur hara makro yaitu Nitrogen (N), fosfor (P), Sulfur (S), Kalium (K), Kalsium (Ca), dan Magnesium $(\mathrm{Mg})$, sedangkan unsur hara mikro yaitu Besi (Fe), Mangan $(\mathrm{Mn})$, Tembaga $(\mathrm{Cu})$, Seng $(\mathrm{Zn})$, Boron (B), Molibdenum (Mo), dan Khlor (Cl). 
Diantara unsur-unsur hara tersebut, Fe merupakan salah satu unsur yang sangat penting. Fe sangat dibutuhkan dalam pembentukan zat hijau daun untuk proses fotosintesis dan pengaktifan berbagai jenis enzim pada tumbuhan. Oleh karena itu keberadaan Fe akan mempengaruhi struktur tanah dan kesuburan tanah (Glinski, 1999). Menurut Mullins (1977) keberadaan $\mathrm{Fe}$ dalam tanah dapat dijadikan indikator kesuburan tanah pada suatu lahan pertanian. Dalam keadaaan stabil, tanah yang tidak terganggu, kenaikan nilai suseptibilitas magnetik tanah paralel dengan keberadaan mineral Fe dari lapisan tanah dasar sampai ke permukaan. Hal ini karena Fe merupakan unsur dengan nilai suseptibilitas magnetik paling tinggi diantara unsur-unsur hara yang lainnya. Oleh karena itu keberadaan $\mathrm{Fe}$ dapat dideteksi melalui pengukuran nilai suseptibilitas tanah untuk menganalisis kondisi tanah (Sadiki dkk, 2009).

Identifikasi kandungan $\mathrm{Fe}$ didalam tanah dapat dilakukan dengan menggunakan Spektrometri X-Ray Fluorescence (XRF). XRF merupakan alat yang digunakan untuk menganalisis komposisi kimia beserta konsentrasi unsur-unsur yang terkandung dalam suatu sampel. Selain itu, metode suseptibilitas magnetik dapat juga digunakan untuk mengidentifikasi kandungan Fe dengan menganalisis nilai suseptibilitas mineral magnetik yang terkandung dalam sampel. Pada metode bisa diketahui keberadaan bulir superparamagnetik yang terdapat pada tanah permukaan. Keberadaan bulir tersebut dapat diketahui dari nilai suseptibilitas bergantung frekuensi (frequency dependent susceptibility), $\chi_{\mathrm{FD}}(\%) . \chi_{\mathrm{FD}}(\%)$ merupakan perbedaan relatif antara suseptibilitas frekuensi rendah $\chi_{\mathrm{LF}}$ dengan frekuensi tinggi $\chi_{\mathrm{HF}}$. Semakin tinggi nilai $\chi_{\mathrm{FD}}$ (\%) maka semakin banyak keberadaan bulir superparamagnetik pada tanah. Tanah yang mengandung bulir superparamagnetik banyak mengandung butiran halus.

Kecamatan Gunung Talang Kabupaten Solok terkenal sebagai daerah penghasil beras terbaik di Provinsi Sumatera Barat. Luas daerah persawahan di Kecamatan Gunung Talang Kabupaten Solok adalah 3.371 ha (BPS, 2016). Untuk meningkatkan hasil panen para petani sering menggunakan pupuk kimia. Penggunaan pupuk kimia yang terus menerus akan menurunkan kualitas tanah pertanian. Penelitian untuk mengetahui kondisi tanah saat ini agar dapat ditanggulangi dan diperbaiki masalah-masalah yang berhubungan dengan kualitas tanah. Disamping itu, hingga saat ini belum pernah dilakukan penelitian untuk mengetahui tingkat pencemaran tanah akibat pemupukan di daerah tersebut.

\section{METODE}

Tempat yang menjadi objek penelitian adalah empat areal persawahan yang berada di Kecamatan Gunung Talang Kabupaten Solok seperti yang terlihat pada Gambar 1. Lahan A yang berada di Nagari Sukarami dengan koordinat $(-0,9306702$. 100,6231832), Lahan B yang berada di Jorong Jawi-Jawi Nagari Guguak (-0,89511 . 100,625687), Lahan C di Jorong Sungai Janiah Nagari Talang (-0,9176876 . 100,6719622), dan Lahan D yang berada di daerah Sawah Rawang Nagari Koto Baru (-0,8479223 . 100,6489545). Sampel diambil sebanyak 41 titik, 40 titik untuk lahan persawahan dan satu titik untuk lahan kosong. Lahan kosong berada di lokasi yang tidak jauh dari lokasi pengambilan sampel untuk lahan persawahan pada lahan A. Sampel diambil menggunakan pipa PVC. Pipa tersebut ditancapkan ke dalam tanah sedalam $15 \mathrm{~cm}$. Tanah yang berada di ujung pipa diambil secukupnya, lalu dimasukkan ke dalam plastik ziplock yang telah diberi tanda. Sampel yang telah diambil dikeringkan pada temperatur kamar selama enam sampai tujuh hari. Pengeringan sampel dilakukan agar uap air yang terkandung pada sampel tanah berkurang. Sampel tanah yang sudah dikeringkan tersebut lalu digerus dan kemudian diayak menggunakan ayakan 100 mesh, untuk selanjutnya dimasukkan ke dalam sample holder. Sample holder kosong ditimbang menggunakan neraca digital. Sampel yang telah diayak kemudian dimasukkan ke dalam sample holder yang telah disiapkan dengan cara dipadatkan. Kemudian diukur massa sample holder yang telah diisi sampel tanah. Pengukuran suseptibilitas magnetik menggunakan MS2B Bartington Susceptibility Meter dengan 15 arah pengukuran. Data dari hasil pengukuran dicatat, kemudian diolah menggunakan program Matlab 2013a dan Microsoft Excel. 


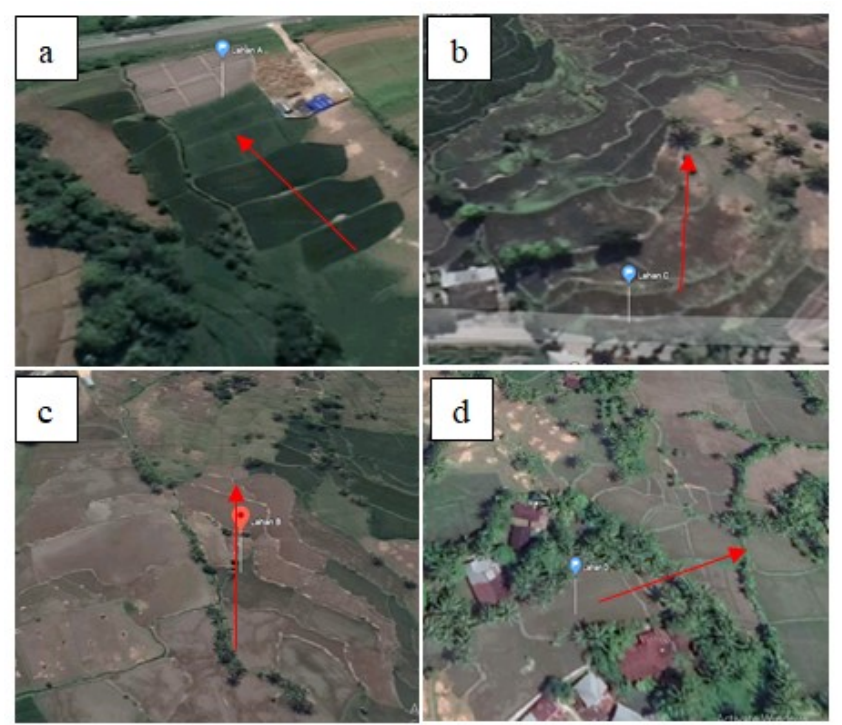

Gambar 1 Lokasi pengambilan sampel pada lahan persawahan (a) Nagari Sukarami (b) Jorong Jawi - Jawi Nagari Guguak (c) Jorong Sungai Janiah Nagari Talang dan (d) Sawah Rawang Nagari Koto Baru

Penentuan jenis dan konsentrasi mineral yang terkandung pada sampel dilakukan menggunakan uji X-Ray Fluorescence (XRF). Sampel yang diuji adalah sampel dari lahan yang memiliki perbedaan nilai suseptibilitas paling mencolok agar terlihat perbedaan kandungannya serta sampel lahan kosong sebagai pembanding. Sampel yang diuji adalah sampel dengan kode B4, B10, D1, D6, dan sampel dari lahan kosong.

\section{HASIL DAN DISKUSI}

\subsection{Hubungan Nilai Suseptibilitas dengan Mineral Magnetik Pada Sampel}

Hasil pengolahan data suseptibilitas magnetik sampel dapat dilihat pada Tabel 1. Secara keseluruhan nilai suseptibilitas untuk masing-masing lahan persawahan jauh lebih rendah dibandingkan dengan lahan kosong yang bernilai lebih dari $500 \times 10^{-8} \mathrm{~m}^{3} / \mathrm{kg}$ untuk masingmasing suseptibilitas $\chi \mathrm{LF}$ dan $\chi \mathrm{HF}$, serta tidak menunjukkan tren menurun sesuai dengan jarak tiap lokasi pengambilan sampel yang semakin jauh dari puncak Gunung Talang.

Rata-rata nilai suseptibilitas $\chi_{\mathrm{LF}}$ untuk lahan A adalah $157,5 \times 10^{-8} \mathrm{~m}^{3} / \mathrm{kg}$ dan rata-rata $\chi_{\mathrm{HF}}$ yaitu $156,0 \times 10^{-8} \mathrm{~m}^{3} / \mathrm{kg}$, untuk lahan B nilai rata-rata $\chi_{\mathrm{LF}}$ naik menjadi $221,3 \times 10^{-8} \mathrm{~m}^{3} / \mathrm{kg}$ serta $\chi_{\mathrm{HF}} 219,5 \times 10^{-8} \mathrm{~m}^{3} / \mathrm{kg}$. Selanjutnya pada lahan $\mathrm{C}$ juga terjadi kenaikan nilai suseptibilitas rata-rata yaitu $222,3 \times 10^{-8} \mathrm{~m}^{3} / \mathrm{kg}$ untuk $\chi_{\mathrm{LF}}$ dan $220,2 \times 10^{-8} \mathrm{~m}^{3} / \mathrm{kg}$ untuk $\chi_{\mathrm{HF}}$. Terakhir untuk lahan D terjadi penurunan yaitu $\chi_{\mathrm{LF}}$ rata-rata $162,6 \times 10^{-8} \mathrm{~m}^{3} / \mathrm{kg}$ dan rata-rata $\chi_{\mathrm{HF}} 160,9 \times 10^{-8}$ $\mathrm{m}^{3} / \mathrm{kg}$. Berdasarkan nilai-nilai suseptibilitas di atas, diperoleh bahwa sampel-sampel dari kedua lokasi dikontrol oleh mineral magnetik yang bersifat paramagnetik dan ferimagnetik.

Jika dibandingkan hasil pengukuran nilai suseptibilitas magnetik $\chi_{\mathrm{LF}}$ dan $\chi_{\mathrm{HF}}$ pada Tabel 1 dapat dilihat bahwa semua sampel memiliki nilai suseptibiltas $\chi_{\mathrm{LF}}$ lebih besar dari pada $\chi_{\mathrm{HF}}$. Hal ini terjadi karena pada pengukuran dengan frekuensi tinggi bulir superparamagnetik tidak berkontribusi dalam menentukan nilai suseptibilitas, yang disebabkan oleh perubahan medan magnetik luar yang dihasilkan lebih cepat dibandingkan waktu relaksasi yang diperlukan untuk bulir superparamagnetik. Hal inilah yang menyebabkan nilai suseptibilitas yang dihasilkan pada pengukuran dengan frekuensi redah lebih tinggi dibandingkan pengukuran dengan frekuensi tinggi.

Penentuan jenis dan konsentrasi mineral yang terkandung pada sampel dilakukan menggunakan uji XRF, hasil dapat dilihat di Tabel 2. Pengujian dilakukan terhadap lima sampel yang terdiri dari satu sampel lahan kosong dan empat sampel lahan persawahan. Sampel lahan persawahan yang dipilih merupakan sampel dari lahan yang memiliki perbedaan nilai suseptibilitas tertinggi dan terendah paling mencolok diantara lahan lainnya. Yaitu sampel dari lahan B dan D dengan kode sampel B4, B10, D1, dan D6. 
Tabel 1 Nilai Suseptibilitas Magnetik Sampel Tanah

\begin{tabular}{|c|c|c|c|c|}
\hline No & Kode Sampel & $\underset{\left(\times 10^{-8} \mathrm{~m}^{3} / \mathrm{kg}\right)}{\chi_{L F}}$ & $\begin{array}{c}\chi_{\mathrm{HF}} \\
\left(\times 10^{-8} \mathrm{~m}^{3} / \mathrm{kg}\right)\end{array}$ & $\begin{array}{l}\chi_{\text {FD }} \\
(\%)\end{array}$ \\
\hline 1 & A1 & 149,7 & 148,6 & 0,73 \\
\hline 2 & $\mathrm{~A} 2$ & 177,0 & 175,2 & 1,02 \\
\hline 3 & A3 & 211,1 & 210,2 & 0,43 \\
\hline 4 & A4 & 132,0 & 131,2 & 0,61 \\
\hline 5 & A5 & 140,6 & 138,4 & 1,56 \\
\hline 6 & A6 & 122,1 & 120,3 & 1,47 \\
\hline 7 & A7 & 165,1 & 163,3 & 1,09 \\
\hline 8 & A8 & 136,7 & 136,2 & 0,37 \\
\hline 9 & A9 & 177,3 & 175,3 & 1,13 \\
\hline 10 & A 10 & 163,5 & 161,5 & 1,22 \\
\hline 11 & B1 & 218,6 & 216,9 & 0,78 \\
\hline 12 & B2 & 223,5 & 221,7 & 0,81 \\
\hline 13 & B3 & 253,8 & 252,4 & 0,55 \\
\hline 14 & B4 & 276,6 & 274,1 & 0,90 \\
\hline 15 & B5 & 251,5 & 248,5 & 1,19 \\
\hline 16 & B6 & 224,8 & 222,5 & 1,02 \\
\hline 17 & B7 & 217,9 & 216,7 & 0,55 \\
\hline 18 & B8 & 212,3 & 210,9 & 0,66 \\
\hline 19 & B9 & 196,1 & 194,4 & 0,87 \\
\hline 20 & B10 & 138,0 & 136,5 & 1,09 \\
\hline 21 & $\mathrm{C} 1$ & 289,3 & 287,0 & 0,80 \\
\hline 22 & $\mathrm{C} 2$ & 215,6 & 213,0 & 1,21 \\
\hline 23 & $\mathrm{C} 3$ & 198,5 & 197,4 & 0,55 \\
\hline 24 & $\mathrm{C} 4$ & 208,0 & 205,3 & 1,30 \\
\hline 25 & $\mathrm{C} 5$ & 241,8 & 239,9 & 0,79 \\
\hline 26 & C6 & 208,8 & 206,6 & 1,05 \\
\hline 27 & $\mathrm{C} 7$ & 191,4 & 189,1 & 1,20 \\
\hline 28 & $\mathrm{C} 8$ & 212,4 & 210,5 & 0,89 \\
\hline 29 & C9 & 202,7 & 199,6 & 1,53 \\
\hline 30 & $\mathrm{C} 10$ & 254,3 & 253,1 & 0,47 \\
\hline 31 & D1 & 225,8 & 223,5 & 1,02 \\
\hline 32 & D2 & 221,6 & 219,5 & 0,95 \\
\hline 33 & D3 & 128,4 & 126,6 & 1,40 \\
\hline 34 & D4 & 129,1 & 126,5 & 2,01 \\
\hline 35 & D5 & 142,9 & 141,9 & 0,70 \\
\hline 36 & D6 & 124,9 & 123,4 & 1,20 \\
\hline 37 & D7 & 156,8 & 154,8 & 1,28 \\
\hline 38 & D8 & 165,8 & 164,4 & 0,84 \\
\hline 39 & D9 & 149,2 & 147,9 & 0,87 \\
\hline 40 & D10 & 181,7 & 180,0 & 0,94 \\
\hline 41 & Lahan Kosong & 570,5 & 564,2 & 1,10 \\
\hline
\end{tabular}

Tabel 2 Jenis dan konsentrasi mineral sampel

\begin{tabular}{|c|c|c|c|c|c|c|c|}
\hline \multirow{2}{*}{ No } & \multirow{2}{*}{ Mineral } & \multicolumn{5}{|c|}{ Konsentrasi Mineral (\%) } & \multirow{2}{*}{ Sifat Magne } \\
\hline & & B4 & B10 & D1 & D6 & Lahan Kosong & \\
\hline 1 & $\overline{\mathrm{SiO}_{2}}$ & 58,643 & 56,448 & 49,785 & 62,801 & 50,965 & Diamagnetik \\
\hline 2 & $\mathrm{Fe}_{2} \mathrm{O}_{3}$ & 6,966 & 6,401 & 8,069 & 7,093 & 16,687 & Ferrimagnetik \\
\hline 3 & $\mathrm{Al}_{2} \mathrm{O}_{3}$ & 30,045 & 32,991 & 34,918 & 25,173 & 15,452 & Paramagnetik \\
\hline 4 & $\mathrm{MgO}$ & 0,329 & 0,602 & 2,017 & 0,226 & 3,974 & Paramagnetik \\
\hline 5 & $\mathrm{SO}_{3}$ & - & 0,958 & 1,640 & - & 3,647 & Diamagnetik \\
\hline 6 & $\mathrm{TiO}_{2}$ & 1,309 & 1,058 & 1,412 & 1,430 & 2,880 & Paramagnetik \\
\hline 7 & $\mathrm{CaO}$ & 0,539 & 0,335 & 0,463 & 0,847 & 2,180 & Diamagnetik \\
\hline 8 & $\mathrm{P}_{2} \mathrm{O}_{5}$ & 1,340 & 0,521 & 0,811 & 1,299 & 1,891 & Paramagnetik \\
\hline 9 & $\mathrm{~K}_{2} \mathrm{O}$ & 0,212 & 0,145 & 0,252 & 0,487 & 0,964 & Paramagnetik \\
\hline
\end{tabular}


Dari Tabel 2 dapat dilihat mineral magnetik yang terkandung dalam adalah $\mathrm{Fe}_{2} \mathrm{O}_{3}$ (hematit) yang bersifat ferrimagnetik, hal ini sesuai dengan perkiraan mineral magnetik berdasarkan nilai suseptibilitas magnetik sampel. Konsentrasi hematit tertinggi adalah pada lahan kosong. Lahan B yang memiliki nilai suseptibilitas magnetik lebih yang tinggi dibanding lahan D ternyata memiliki konsentrasi hematit yang lebih rendah dibandingkan dengan konsentrasi hematit pada lahan D. Hal ini diduga karena selisih perbedaan konsentrasi hematit pada kedua lahan tersebut yang tidak begitu signifikan.

Berdasarkan letak bidang sawah pada tiap lahan, konsentrasi hematit tertinggi terdapat pada lahan dengan posisi atas yaitu sampel B4 dan D1. Hal ini sesuai dengan nilai suseptibilitas magnetik sampel bidang atas yang lebih tinggi dibandingkan bidang bagian bawah. Jadi, secara keseluruhan bisa dikatakan bahwa nilai suseptibilitas magnetik sampel bergantung pada konsentrasi mineral magnetik yang terkandung di dalam sampel.

Nilai suseptibilitas magnetik mineral dalam suatu batuan dikontrol oleh sifat mineralnya yaitu ferimagnetik dan paramagnetik. Hal ini dibuktikan dengan hasil uji XRF bahwa dalam sampel di samping terkandung mineral bersifat ferimagnetik, juga terdapat mineral yang bersifat paramagnetik seperti $\mathrm{Al}_{2} \mathrm{O}_{3}, \mathrm{CaO}, \mathrm{MgO}, \mathrm{TiO}_{2}, \mathrm{~K}_{2} \mathrm{O}$ dan diamagnetik seperti $\mathrm{SO}_{3}, \mathrm{SiO}_{2}$ dan $\mathrm{P}_{2} \mathrm{O}_{5}$. Keberadaan mineral diagmanetik tidak akan mempengaruhi nilai suseptibilitas karena memiliki nilai suseptibilitas negatif.

\subsection{Hubungan $\chi \mathrm{FD}(\%)$ dengan Kondisi Lahan}

Pada Tabel 1 bisa dilihat nilai $\chi_{\mathrm{FD}}(\%)$ yang diperoleh berada pada kisaran yang sama. Nilai $\chi_{\mathrm{FD}}(\%)$ pada lahan kosong adalah $1,10 \%$, untuk lahan sawah pertama nilai $\chi_{\mathrm{FD}}(\%)$ berada pada rentang $0,37 \%$ - $1,56 \%$ dengan rata-rata yaitu $0,96 \%$, selanjutnya untuk lahan kedua berada pada rentang $0,55 \%$ - 1,19\% dengan rata-rata $0,84 \%$, lahan ketiga memiliki rentang $\chi_{\mathrm{FD}}(\%)$ pada $0.47 \%$ - $1,53 \%$ dengan rata-rata sebesar $0,98 \%$, dan untuk lahan keempat berada pada rentang $0,7 \%-2,0 \%$ dengan rata-rata $1,12 \%$.

Sebaran nilai $\chi_{\mathrm{FD}}(\%)$ dapat dilihat pada Gambar 2. Lahan persawahan dan lahan kosong rata-rata semua sampel memiliki nilai $\chi_{\mathrm{FD}}(\%)$ yang berada dalam rentang $0 \%-2 \%$. Hal ini menunjukkan bahwa domain magnetik pada sampel tersebut terdiri dari Single Domain (SD) dan Multi Domain (MD) dan tidak ada atau kurang dari 10\% bulir superparamagnetik. Lahan kosong dan lahan persawahan semuanya memiliki nilai $\chi_{\mathrm{FD}}(\%)$ kurang dari $2 \%$. Keberadaan bulir superparamagnetik pada tanah mengindikasikan bahwa keseluruhan tanah memiliki butiran yang halus. Semakin banyak bulir superparamagnetik yang terkandung dalam tanah, semakin banyak butiran halus yang dimiliki oleh tanah tersebut (Pratiwi dkk, 2016). Bisa dikatakan tanah pada lahan kosong dan lahan persawahan dengan nilai $\chi_{\mathrm{FD}}(\%)$ kurang dari $2 \%$ masih memiliki kesuburan tanah yang baik untuk bercocok tanam.

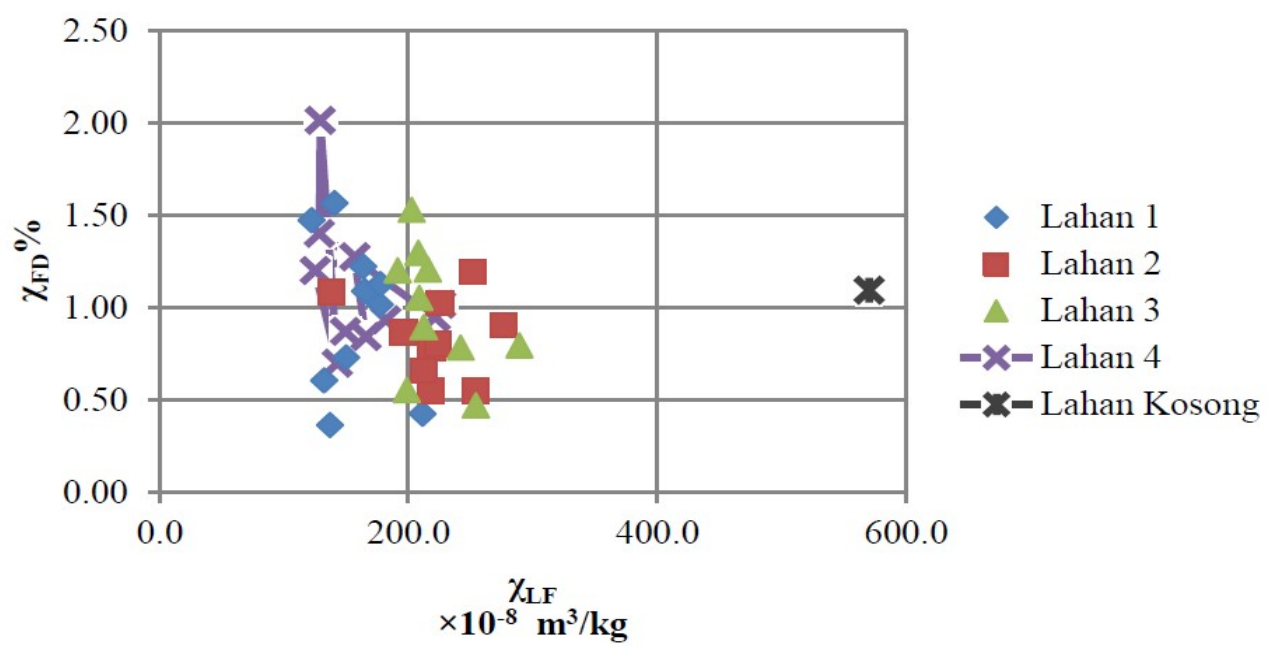

Gambar 2 Grafik hubungan antara nilai suseptibilitas magnetik frekuensi rendah terhadap $\chi_{\mathrm{FD}}(\%)$ 


\subsection{Hubungan Nilai Suseptibilitas Magnetik, Kandungan Fe dengan Kesuburan tanah}

Hubungan suseptibilitas magnetik dengan kandungan Fe dalam tanah dapat dilihat pada Gambar 3. Nilai suseptibilitas magnetik sampel tanah tidak selalu bergantung pada kandungan Fe sampel. Dapat dilihat pada sampel B4 yang memiliki nilai suseptibilitas magnetik yang lebih tinggi dibandingkan dengan sampel D1 ternyata memiliki kandungan Fe yang lebih kecil. Begitu juga untuk B10 dengan D6, dimana B10 meliliki suseptibilitas lebih tinggi namun memiliki kandungan $\mathrm{Fe}$ yang lebih rendah. Jika dibandingkan dengan lahan kosong, keempat sampel memiliki kandungan Fe yang jauh lebih rendah, sesuai dengan nilai susptibilitas keempat sampel lahan persawahan yang jauh lebih rendah dibanding lahan kosong.

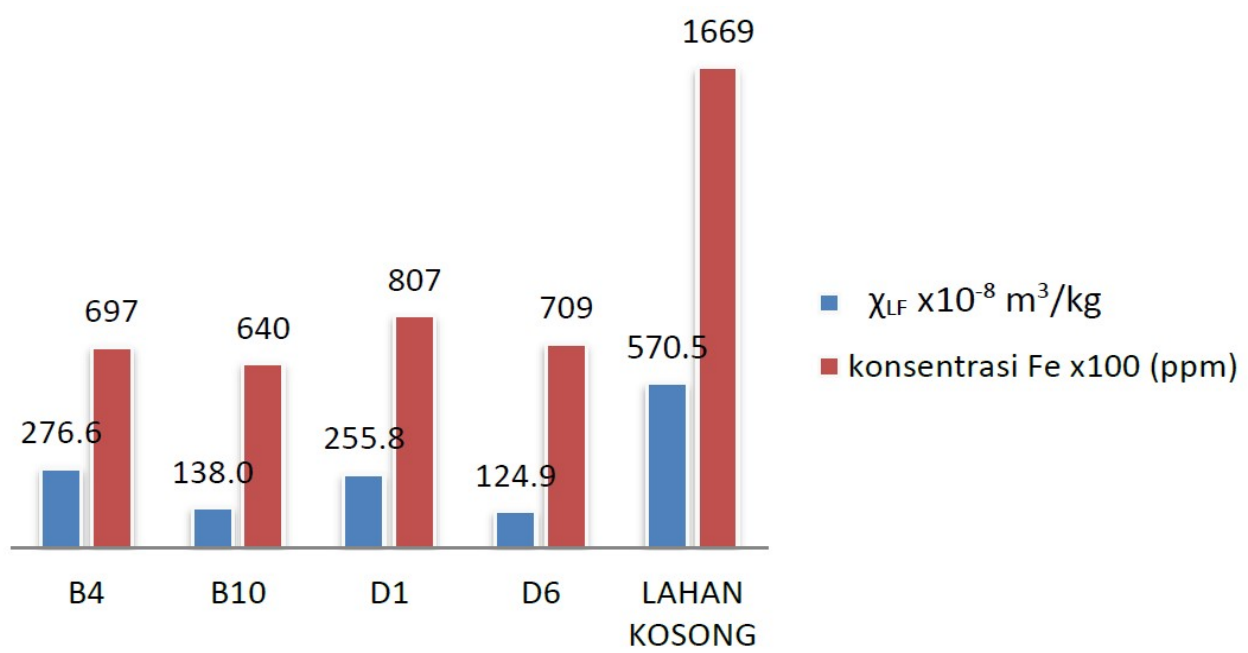

Gambar 3 Hubungan suseptibilitas magnetik dengan kandungan Fe

Perbedaaan kandungan Fe dengan nilai susptibilitas magnetik sampel ini terjadi karena usia lahan persawahan tempat pengambilan sampel yang relatif sama, yang berdampak pada masa pemakaian lahan yang juga hampir sama. Selain itu, perbedaan juga terjadi karena nilai suseptibilitas magnetik lahan tidak hanya ditentukan oleh kandungan Fe. Sebagaimana telah dijelaskan sebelumnya, nilai suseptibilitas magnetik lahan dikontrol oleh mineral ferimagnetik dan paramagnetik. Jadi nilai suseptibilitas magnetik juga ditentukan oleh keberadaan mineral paramagnetik seperti $\mathrm{Al}_{2} \mathrm{O}_{3}, \mathrm{CaO}$, dan lain-lain.

Setiap tanaman membutuhkan kadar $\mathrm{Fe}$ yang berbeda-beda sehingga membuat banyaknya pemberian pupuk berbeda-beda pula. Pemberian pupuk kimia menyebabkan kadar Fe dalam tanah berkurang yang disebabkan oleh tingginya penyerapan $\mathrm{N}$ dan $\mathrm{P}$ sehingga mendorong berkurangnya kadar Fe dalam tanah (Ayu, 2009). Berdasarkan tempat pengambilan sampel, tanah memiliki kandungan Fe yang berlebih sehingga dikhawatirkan tanaman menyerap Fe terlalu banyak yang menyebabkan terhambatnya penyerapan unsur hara yang lainnya. Oleh karena itu diperlukan pemberian pupuk urea guna menyediakan unsur makro seperti N, P, K agar tanaman menyerap unsur hara yang seimbang. Dengan demikian, tempat pengambilan sampel masih memiliki kesuburan tanah yang baik untuk bercocok tanam.

Berdasarkan Tabel 2 hasil uji XRF, tanah tempat pengambilan sampel merupakan tanah dengan tekstur berlempung karena tersusun atas senyawa $\mathrm{SiO}_{2}$ dan $\mathrm{Al}_{2} \mathrm{O}_{3}$ serta cadangan unsur hara seperti $\mathrm{Fe}_{2} \mathrm{O}_{3}, \mathrm{~K}_{2} \mathrm{O}$, CaO dll. Dari penjelasan tersebut bisa ditarik kesimpulan bahwa tanah pada lahan persawahan masih dalam kondisi baik untuk bercocok tanam dibandingkan lahan kosong yang memiliki kandungan Fe di atas batas normal.

\section{KESIMPULAN}

Nilai suseptibilitas lahan kosong lebih tinggi dibandingkan dengan lahan persawahan. Dimana lahan A memiliki nilai suseptibilitas magnetik $\left(\chi_{\mathrm{LF}}\right)$ rata-rata $157,5 \times 10^{-8} \mathrm{~m}^{3} / \mathrm{kg}$, lahan B dengan rata-rata $221,3 \times 10^{-8} \mathrm{~m}^{3} / \mathrm{kg}$, lahan $\mathrm{C}$ dengan rata-rata $222,3 \times 10^{-8} \mathrm{~m}^{3} / \mathrm{kg}$, lahan $\mathrm{D}$ dengan rata-rata $162,6 \times 10^{-8} \mathrm{~m}^{3} / \mathrm{kg}$, dan lahan kosong dengan nilai $570,5 \times 10^{-8} \mathrm{~m}^{3} / \mathrm{kg}$. Nilai suseptibilitas magnetik sampel lahan kosong dan lahan persawahan dikontrol oleh mineral paramagnetik dan 
ferimagnetik. Hasil uji XRF terbukti bahwa mineral magnetik yang terkandung pada sampel adalah hematit. Semakin tinggi konsentrasi hematit pada sampel semakin tinggi nilai suseptibilitas magnetik. Lahan kosong dan lahan persawahan semuanya memiliki nilai $\chi_{\mathrm{FD}}(\%)$ kurang dari $2 \%$ masih memiliki kesuburan tanah yang baik untuk bercocok tanam.

\section{DAFTAR PUSTAKA}

Almiati R. dan Agustin E., Analisis Kesuburan Tanah dan Residu Pemupukan pada Tanah dengan Menggunakan Metode Kemagnetan Batuan, Jurnal Ilmu dan Inovasi Fisika, 1(2), 52-61, 2017.

Ayu, L.K., Pengaruh Pemberian Pupuk Urea dan Dolomit Terhadap Perubahan pH Tanah, Serapan N dan P serta Pertumbuhan Tanaman Jagung (Zea Mays) pada Ultisol, Skripsi, Universitas Sumatera Utara, 2009.

Glinski J. dan Horabik, J., Encyclopedia of Agrophysics, Netherlands, Spinger, 2011.

Haris V., Studi Awal Perubahan Sifat Magnetik Tanah Akibat Pemakaian Pupuk Kimia, Jurnal Sainstek, 5(2), 97-102, 2013.

Katalog BPS, Luas Lahan Menurut Penggunaan Kabupaten Solok 2016, Badan Pusat Statistik Kabupaten Solok:Solok, 2016.

Mullins, C. E, Magnetic Susceptibility Of The Soil And Its Significance In Soil Science - A Review, Journal of Soil Science, 28(2), 223-246, (1977).

Pratiwi, R. A., Prakoso, A. G., Darmasetiawan, R., Agustine, E., Kirana, K. H., Fitriani, D., Identifikasi Sifat Magnetik Tanah di Daerah Tanah Longsor, Prosiding Seminar Nasional Fisika (E-journal) SNF2016, 5(1), 182-187, 2016.

Sadiki, A., Faleh, A., Navas, A., \& Bouhlassa, S., Using magnetic susceptibility to assess soil degradation in the Eastern Rif, Morocco. Earth Surface Processes and Landforms, 34(15), 2057-2069, 2009.

Schroeder D., 1984. Soils-Facts and Concepts, International Potash Institude:Bern.

Friyandito, Mekanisme Serapan Hara Oleh Tanaman, https://bestplanterindonesia.com/mekanisme-serapan-hara-oleh-tanaman/, 2017 (diakses April 2019). 